\title{
Adult Subventricular Zone Neuronal Precursors Continue to Proliferate and Migrate in the Absence of the Olfactory Bulb
}

\author{
Barry Kirschenbaum, ${ }^{1}$ Fiona Doetsch, ${ }^{1}$ Carlos Lois, ${ }^{2}$ and Arturo Alvarez-Buylla ${ }^{1}$ \\ 1The Rockefeller University, New York, New York 10021, and ²California Institute of Technology, Pasadena, California 91125
}

Neurons continue to be born in the subventricular zone (SVZ) of the lateral ventricles of adult mice. These cells migrate as a network of chains through the SVZ and the rostral migratory stream (RMS) into the olfactory bulb (OB), where they differentiate into mature neurons. The $\mathrm{OB}$ is the only known target for these neuronal precursors. Here, we show that, after elimination of the OB, the SVZ and RMS persist and become dramatically larger. The proportion of dividing [bromodeoxyuridine (BrdU)-labeled] or dying (pyknotic or terminal deoxynucleotidyl transferase-mediated biotinylated UTP nick end-labeled) cells in the RMS was not significantly affected at $3 \mathrm{~d}$ or 3 weeks after bulbectomy (OBX). However, by 3 months after OBX, the percentage of BrdU-labeled cells in the RMS decreased by half and that of dying cells doubled. Surprisingly, the rostral migration of precursors continued along the RMS after OBX. This was demonstrated by focal microinjections of BrdU and grafts of SVZ cells carrying LacZ under the control of a neuronspecific promoter gene. Results indicate that the $O B$ is not essential for proliferation and the directional migration of SVZ precursors.

Key words: bulbectomy; adult; subventricular zone; neuronal precursors; subependymal layer; cell death
The adult rodent olfactory bulb $(\mathrm{OB})$ is constantly being supplied with newly generated neurons (Hinds, 1968; Altman, 1969; Bayer, 1983; Corotto et al., 1993; for review, see Farbman, 1990; Alvarez-Buylla, 1997). These cells originate $6-8 \mathrm{~mm}$ caudally in the subventricular zone (SVZ) of the lateral ventricles (Luskin, 1993; Lois and Alvarez-Buylla, 1994). The SVZ precursors migrate through a network of tangential pathways in the lateral wall of the lateral ventricle (Doetsch and Alvarez-Buylla, 1996) and then converge onto the rostral migratory stream (RMS), which leads into the core of the OB. Cells in the SVZ network and RMS move rapidly by chain migration without axonal or radial glial guides (Doetsch and Alvarez-Buylla, 1996; Jankovski and Sotelo, 1996; Lois et al., 1996; Wichterle et al., 1997). Within the OB, these young neurons leave the RMS and migrate into the granule and periglomerular layers, where they differentiate into local interneurons.

How is the proliferation and migration of these neuronal precursors regulated in the adult brain? Growth factors (epidermal growth factor and fibroblast growth factor) increase the proliferation of SVZ neuronal precursors in vivo (Craig et al., 1996; Kuhn et al., 1997) and in vitro (Reynolds and Weiss, 1992; Richards et al., 1992; Gritti et al., 1995, 1996). In vitro, the maturation and survival of SVZ-generated neurons is partly under the control of brain-derived neurotrophic factor (Ahmed et al., 1995; Kirschenbaum and Goldman, 1995). However, the role of these factors and the source of regulatory signals in vivo are not known. The OB is the only known target for migration of SVZ young neurons in the adult brain. Target-derived factors guide the migration of axons in the developing brain (Tessier-Lavigne et al., 1988; Yaginuma et al., 1994) and play a critical role in the differentiation and

\footnotetext{
Received June 5, 1998; revised Dec. 9, 1998; accepted Jan. 8, 1999.

This work was supported by National Institutes of Health Grants HD32116 and NS28478 to A.A.B. and DC03046 to B.K. We thank B. Haripal for help with tissue processing and D. Lim for suggestions on this manuscript.

Correspondence should be addressed to Dr. Arturo Alvarez-Buylla, The Rockefeller University, 1230 York Avenue, Box 210, New York, NY 10021.

Copyright (C) 1999 Society for Neuroscience $0270-6474 / 99 / 192171-10 \$ 05.00 / 0$
}

survival of neurons (Chao, 1992; Linden, 1994). Similarly, OBderived factors could influence the migration and regulate the proliferation and survival of SVZ precursors. The trophic function of the $\mathrm{OB}$ for the survival and replacement of olfactory receptor neurons has been extensively documented (Farbman, 1990; Monti-Graziadei and Graziadei, 1992; Schwob et al., 1992). In contrast, the role of the $\mathrm{OB}$ in the migration and proliferation of SVZ precursors has not been directly tested.

Previous studies suggest that olfactory deprivation by naris closure does not affect the proliferation, survival, or migration of the majority of precursors in the SVZ and RMS (Frazier-Cierpial and Brunjes, 1989; Corotto et al., 1994). These experiments, however, do not preclude the possibility that the OB secretes factors that influence RMS cell proliferation, survival, or migration independently of odor stimulation. Here, we have tested whether OB removal affects the proliferation, migration, differentiation, and survival of adult SVZ-generated neurons. Results indicate that SVZ cells continue to divide and migrate anteriorly in the absence of the OB.

\section{MATERIALS AND METHODS}

Animals and $O B$ removal. Adult male (2-3 months of age) CD-1 mice (Charles River Laboratories, Wilmington, MA) were used for all experiments. For OB removal, mice were anesthetized with Nembutal (50 $\mathrm{mg} / \mathrm{kg}$ body weight, i.p.; Abbott Labs, Irving, TX), and the right OB was exposed via a dorsal craniotomy and then removed by aspiration. In sham controls, craniotomy was performed, but the OB was not aspirated. After OB removal, the ensuing cavity was filled with Gelfoam (Upjohn, Kalamazoo, MI), and the overlying skin was closed with cyanoacrylate glue. The lesion extended into the olfactory peduncle and included part of the anterior olfactory nuclei. There was no damage to the contralateral OB or the ipsilateral cortex or striatum. Animals were killed by an overdose of Nembutal ( $250 \mathrm{mg} / \mathrm{kg}$ body weight, i.p.) $3 \mathrm{~d}, 3$ weeks, and 3 months (see below) after bulb removal (OBX). All animal procedures were in accordance with The Rockefeller University guidelines.

Local SVZ microinjection of thymidine analogs. Bromodeoxyuridine (BrdU) (Sigma, St. Louis, MO) or $\left[{ }^{3} \mathrm{H}\right]$ thymidine $\left(\left[{ }^{3} \mathrm{H}\right] \mathrm{T}\right)(6.7 \mathrm{Ci} / \mathrm{mmol}$, $1 \mathrm{mCi} / \mathrm{ml}$; New England Nuclear, Boston, MA) was used to label a local cohort of SVZ cells in S phase as described previously (Lois and Alvarez-Buylla, 1994). Briefly, $10 \mathrm{nl}$ of $\left[{ }^{3} \mathrm{H}\right] \mathrm{T}$ (plus $0.2 \%$ Fluoro-Gold to 
mark the position of the microinjections) or $10 \mathrm{nl}$ of $\mathrm{BrdU}(10 \mathrm{mg} / \mathrm{ml})$ was bilaterally microinjected into the SVZ (stereotaxic coordinates: 1 $\mathrm{mm}$ anterior to bregma; $1.0 \mathrm{~mm}$ lateral to the midline; and $2.1 \mathrm{~mm}$ deep from the pial surface) of adult male mice that had undergone unilateral OBX $2(n=6)$ or $11(n=4)$ weeks before microinjections. Mice were killed 1 week later. Animals were intracardially perfused with $0.9 \%$ $\mathrm{NaCl}$, followed by $3.0 \%$ paraformaldehyde, and the brains were postfixed overnight in the same fixative. Brains were embedded in polyethyleneglycol (PEG) (Alvarez-Buylla et al., 1987) and sectioned sagittally at $6 \mu \mathrm{m}$ and every tenth section, which included the RMS mounted on silianated coated slides. Sections were processed for either autoradiography (Alvarez-Buylla et al., 1988) or BrdU immunocytochemistry (Lois and Alvarez-Buylla, 1994) and counterstained with Hoechst 33258 (50 $\mu \mathrm{g} / \mathrm{ml})$. Some animals $(n=3)$ received a microinjection of BrdU into the $\mathrm{SVZ}$ as above and were killed at $4 \mathrm{hr}$ instead of 1 week to confirm that the microinjection had labeled a restricted region of the SVZ. In these animals, labeled cells were restricted to a radius of $500 \mu \mathrm{m}$ from the injection site, and no labeled cells were observed in the rostral two-thirds of the RMS (see Fig. 5).

SVZ grafts from NSE::LacZ mice. SVZ was dissected from postnatal day 5 (P5) transgenic mice that carry the $\beta$-galactosidase gene (LacZ) under the control of the neuron-specific enolase (NSE) promoter (NSE::LacZ; kindly provided by Drs. S. Forss-Petter and P. Danielson, Scripps Institute, La Jolla, CA) (Forss-Petter et al., 1990) and minced into $\sim 100 \mu \mathrm{m}$ explants in L-15 medium (Life Technologies, Gaithersburg, MD). NSE::LacZ explants were grafted bilaterally into the SVZ of adult CD-1 mice (Lois and Alvarez-Buylla, 1994) either $2(n=3)$ or 8 $(n=3)$ weeks after unilateral OBX. Four weeks later, mice were killed and perfused with fixative as above. The brains were post-fixed for 30 min and incubated in 30\% sucrose overnight. Sagittal $60 \mu \mathrm{m}$ sections were cut on a freezing microtome, and serial sections were incubated overnight at $37^{\circ} \mathrm{C}$ in $2 \mathrm{~mm} \mathrm{MgCl}_{2}, 0.01 \%$ deoxycholic acid, $0.02 \%$ Nonidet P-40, $4 \mathrm{~mm}$ potassium ferrocyanide, $4 \mathrm{~mm}$ potassium ferricyanide, and $1 \mathrm{mg} / \mathrm{ml} 5$-bromo-4-chloro-3-indolyl $\beta$-D-galactoside (Molecular Probes, Eugene, OR) in PBS, pH 7.3, to reveal $\beta$-galactosidasepositive cells (see Fig. 6). Sections were washed in PBS, mounted on slides, and counterstained with Hoechst 33258.

Polysialylated form of the neural cell adhesion molecule immunohistochemistry. Three days $(n=3), 3$ weeks $(n=3)$, and 3 months $(n=2)$ after OBX, animals were perfused with $3 \%$ paraformaldehyde, and the brains were removed and fixed overnight. Serial frontal sections $(50 \mu \mathrm{m})$ were cut on a Vibratome and were stained with antibodies against the polysialylated form of the neural cell adhesion molecule (PSA-NCAM) (1:2000; a gift from Genevieve Rougon, Centre National de la Recherche Scientifique, Université de Luminy, Marseille, France) (Rougon et al., 1986). The area of PSA-NCAM staining, equivalent to the area of the RMS and SVZ, was measured in the bulbectomized and contralateral hemispheres at six different rostrocaudal levels, starting with the level of OBX (+2.0 mm relative to bregma) and ending at the crossing of the anterior commissure $(+0.1 \mathrm{~mm}$ relative to bregma) using a stereotaxic atlas as a reference (Slotnick and Leonard, 1975). A digital image of each level (bulbectomy and contralateral) was acquired with a SPOT camera (Diagnostic, Sterling Heights, MI). The area of PSA-NCAM immunostaining was then measured with NIH Image analysis software (version 1.62), and the ratio of the area of the OBX to the contralateral side was calculated. The size of the RMS in the hemisphere contralateral to the bulbectomy did not change significantly at different survivals after OBX and was similar to the RMS in sham-operated controls without OBX (see Fig. 2). To visualize the entire SVZ, whole mounts of the lateral wall of the lateral ventricle were dissected 3 weeks $(n=4)$ and 3 months $(n=$ 4) after OBX and immunostained with PSA-NCAM antibodies as described previously (Doetsch and Alvarez-Buylla, 1996).

$S V Z$ cell proliferation. Unilaterally bulbectomized mice were allowed to survive for $3 \mathrm{~d}(n=3)$, 3 weeks $(n=4)$, or 3 months $(n=4)$. Four hours before killing, mice were injected with $\operatorname{BrdU}(50 \mathrm{mg} / \mathrm{kg}$ body weight; i.p.) and perfused as described above. Brains were equilibrated in $30 \%$ sucrose overnight before freezing in O.C.T. compound (Tissue-Tek) and cutting on a cryostat. Brains were sectioned sagittally at $10 \mu \mathrm{m}$ and every sixth section, which included the RMS, was mounted and stained with anti-BrdU antibodies (Vector Laboratories, Burlingame, CA). The sections were incubated overnight in $5 \%$ sodium bicarbonate and counterstained with Hoechst 33258 as described above.

Cell death in the SVZ (pyknotic and terminal deoxynucleotidyl transferase-mediated biotinylated UTP nick end labeling technique). The right $\mathrm{OB}$ was removed, and animals were killed 3 weeks $(n=6)$ or 3 months $(n=4)$ after OBX. Sagittal $6 \mu \mathrm{m}$ PEG sections were prepared as above, incubated at $60^{\circ} \mathrm{C}$ for $30 \mathrm{~min}$, delipidized with xylene, and rehydrated in ethanol. DNA fragmentation was detected by the terminal deoxynucleotidyl transferase-mediated biotinylated UTP nick end labeling (TUNEL) staining method (Gavrieli et al., 1992; Holcomb et al., 1995) and visualized with avidin-FITC (Vector Laboratories) (see Fig. $8 B)$. Pyknotic cells were identified by their condensed chromatin in Hoechst 33258-stained sections (see Fig. 8A).

Image analysis and quantification. Cell counts and area measurements were performed using a computer-based mapping microscope (AlvarezBuylla and Vicario, 1988). The area of the RMS was determined (60X magnification) in sagittal sections $60 \mu \mathrm{m}$ apart, and the volume was calculated. The RMS is easily distinguishable from surrounding tissue because of its higher cell density. The caudal limit of the RMS was defined in sagittal sections as the point, $0.8-1.1 \mathrm{~mm}$ lateral from the midline, at which the lumen of the lateral ventricle opens up at the interface of the corpus callosum and striatum. The rostral limit was defined as the point at which the $\mathrm{OB}$ begins and, in the case of $\mathrm{OB}$ removal, to the edge of the tissue. Cell density was determined by counting the number of cells in three separate fields along the RMS (630× magnification). The total area of the RMS from these sections was also measured to estimate the total number of RMS cells. This was done by multiplying the area by the density. Total numbers of BrdU, pyknotic, and TUNEL-labeled cells were counted (200× magnification) along the extent of the RMS in five evenly spaced sections.

\section{RESULTS}

\section{The RMS persists after OB removal}

The OB of adult mice was removed unilaterally, and animals were allowed to survive for $3 \mathrm{~d}, 3$ weeks, or 3 months. Sagittal sections of the brain revealed that in the operated hemispheres $(3 \mathrm{~d}, n=$ 3; 3 weeks, $n=6$; 3 month, $n=4$ ) a prominent RMS was present (Fig. 1). As in animals with an intact bulb, the RMS was composed of highly packed small cells that were clearly distinguishable from the surrounding brain parenchyma. The RMS has an S shape that begins at the dorsal and lateral wall of the anterior horn of the lateral ventricle, curves ventrally between the corpus callosum and striatum, and then turns rostrally to reach the OB. On the bulbectomized side, the path followed by the RMS was identical to controls, but the RMS was enlarged.

\section{The RMS increases in volume after OBX}

We measured the volume of the RMS in the bulbectomized hemisphere and compared it with the RMS in the contralateral side. Three days after OBX, there was a slight increase in the RMS on the bulbectomized side (Fig. 2), but this increase did not reach statistical significance ( $p=0.38$; Mann-Whitney $U$ test). By three weeks after OBX, the RMS volume on the bulbectomized side had increased significantly by $49.3 \% \quad(p=0.03$; Mann-Whitney $U$ test) (Fig. 2) compared with control. By 3 months, the RMS on the OBX side had doubled in volume ( $p=$ 0.02; Mann-Whitney $U$ test) (Fig. 2). Sham-operated controls at 3 months $(n=5)$ showed no significant difference $(p=0.92$; Mann-Whitney $U$ test) compared with the unoperated hemisphere (Fig. 2). We counted the number of nuclei in the RMS at the different survivals after OBX and calculated the corresponding cell densities. No significant differences in RMS cell-packing densities were observed at any of the three survival times studied (Fig. 3). This indicates that RMS cell number after OBX increased proportionally to the increase in volume.

\section{The network of pathways for chain migration in the SVZ and RMS enlarges after OBX}

Young neurons destined for the OB migrate through a network of tangential pathways in the SVZ and join the RMS in the dorsolateral anterior lateral ventricle (Doetsch and Alvarez-Buylla, 1996). PSA-NCAM is expressed by migrating young neurons in 


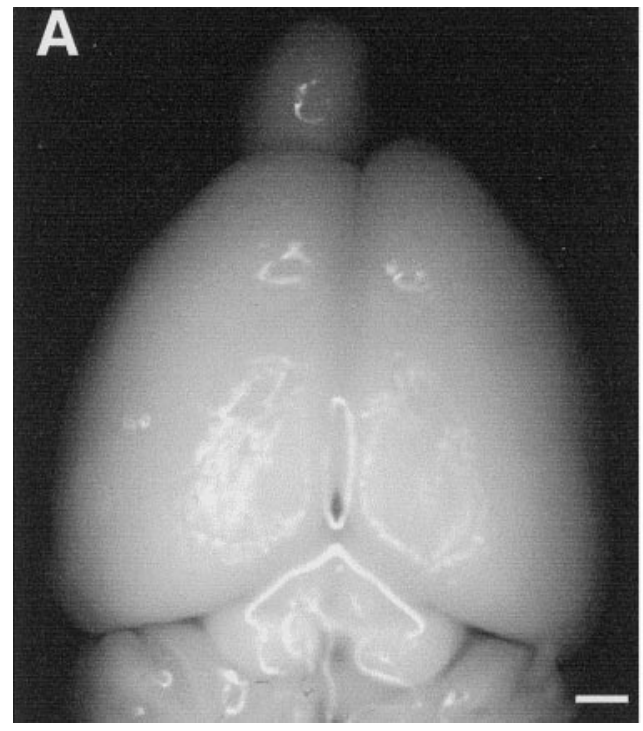

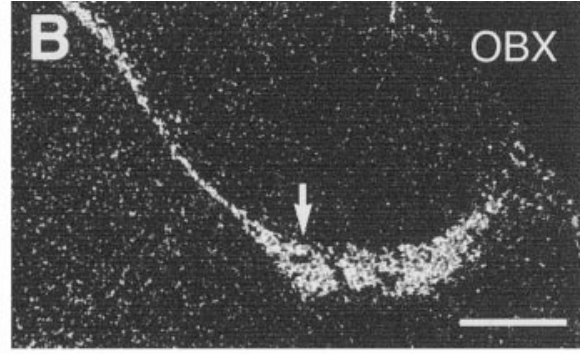

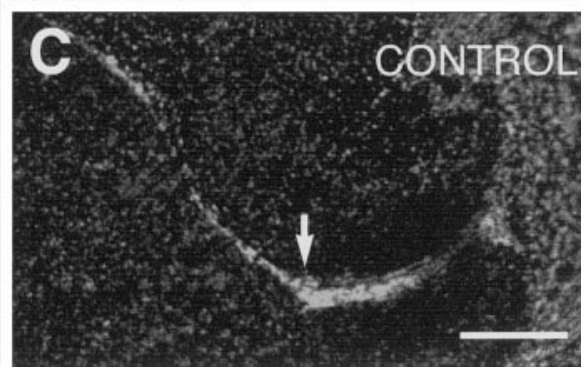

Figure 1. Effect of OBX on the RMS of adult mice. $A$, The $\mathrm{OB}$ was removed on the right hemisphere. $B, C$, After OBX, the RMS (arrows) was significantly larger on the bulbectomized hemisphere $(B)$ compared with the control $(C) . B$ and $C$ show sagittal sections of the anterior forebrain stained with Hoechst 33258 3 months after OBX. Scale bars, $0.5 \mathrm{~mm}$.

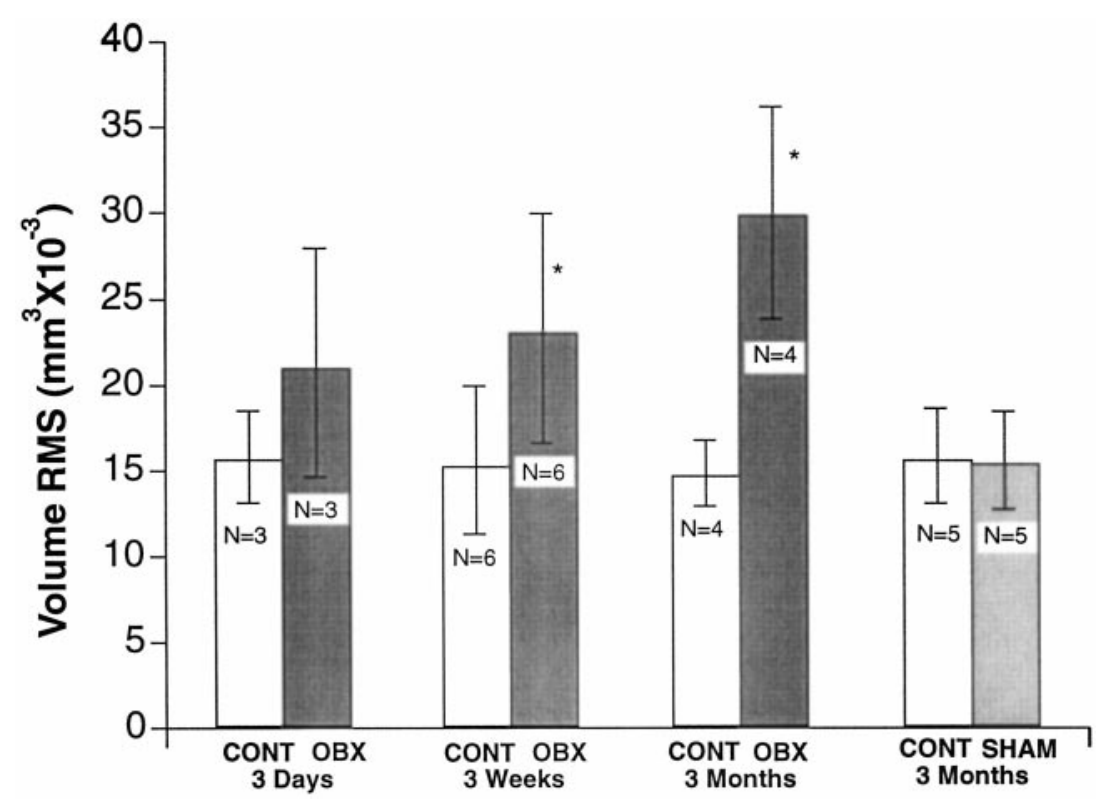

Figure 2. Volume of the RMS after OBX in the contralateral control $(C O N T)$ side and in sham-operated controls. A trend toward increase in RMS volume after OBX was observed already by $3 \mathrm{~d}$. This increase was significant at the survival times of 3 weeks and 3 months. ${ }^{*} p<0.03$; Mann-Whitney $U$ test. Error bars indicate mean \pm SD. the SVZ and RMS (Bonfanti and Theodosis, 1994; Rousselot et al., 1995). This adhesion molecule plays a critical role in homotypic interactions during chain migration (Tomasiewicz et al., 1993; Cremer et al., 1994; Ono et al., 1994). Frontal sections showed that the RMS and SVZ, as revealed by PSA-NCAM immunohistochemistry, increased dramatically in size after OBX (Fig. $4 A-F)$. The increase in the area of PSA-NCAM staining was quantified at different rostrocaudal levels and at different survivals after OBX (Fig. 4). Three days after OBX, the increase in the area of PSA-NCAM staining was most noticeable in rostral and intermediate RMS ( +2.0 and $+1.7 \mathrm{~mm}$, relative to bregma). At 3 days, the anterior RMS area was three to four times larger in the bulbectomized hemisphere compared with the control, but caudal to $+1.4 \mathrm{~mm}$, the area of PSA-NCAM staining was similar in both hemispheres. By 3 weeks and 3 months, the increase in the PSA-NCAM stained area was evident not only in the anterior RMS, but also in the caudal RMS and in the anterior SVZ. Results indicate that the RMS increases in size beginning anteriorly (close to the site of $\mathrm{OBX}$ ) and that this increase progresses caudally as time passes after OBX.

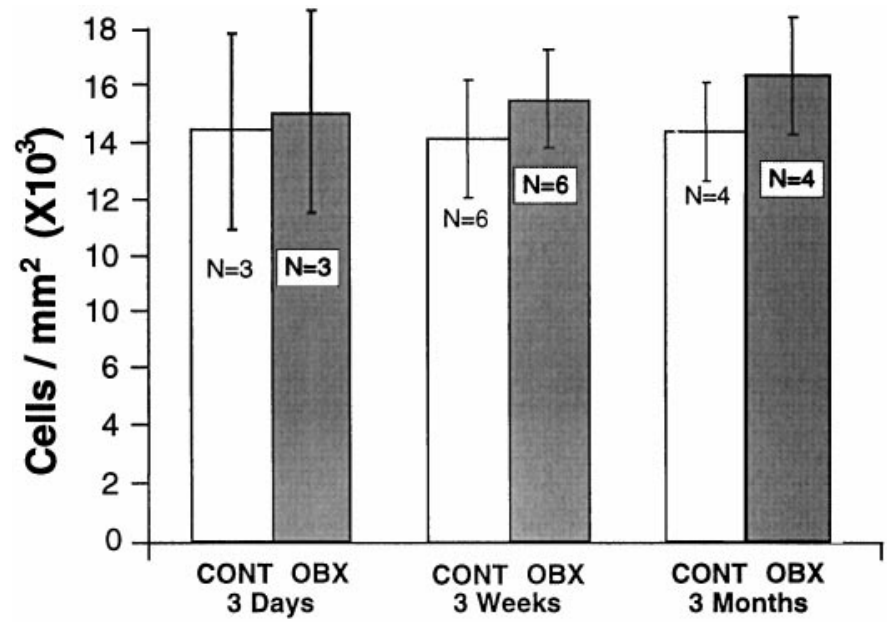

Figure 3. Density of cells in the RMS after OBX compared with control side $(C O N T)$. A small, nonsignificant increase was observed at all survival times; $p>0.05$; Mann-Whitney $U$ test. Error bars indicate mean \pm SD. 




Figure 4. The size of the RMS and SVZ, as revealed by PSA-NCAM immunostaining, increases after OBX. $A-F$, Frontal sections through the RMS $(A, D)$ and SVZ $(B, C, E, F) 3$ weeks $(A-C)$ and 3 months $(D-F)$ after OBX. At 3 weeks after OBX, the RMS in the bulbectomized hemisphere is much larger than in controls $(A$, arrows). At this survival, the SVZ of the bulbectomized hemisphere is only slightly larger $(C$, arrow). By 3 months, both the RMS and SVZ have greatly increased in size $(D-F)$. G, Quantification of the area of PSA-NCAM staining in frontal sections at different rostrocaudal levels $3 \mathrm{~d}(n=3), 3$ weeks $(n=3)$, and 3 months $(n=2)$ after OBX. The $y$-axis indicates the percent increase in area of the RMS and SVZ in the operated side compared with the control hemisphere. The increase in size is first noticeable at $3 \mathrm{~d}$ in the rostral and intermediate RMS. With longer survivals after OBX, the RMS and SVZ become progressively enlarged in more caudal regions. $H, I$, The network of pathways for chain migration in the SVZ enlarges after OBX. En face dissections of the lateral wall of the lateral ventricle stained with PSA-NCAM antibodies show the chains in this network in the control $(H)$ and bulbectomized $(I)$ sides. Notice the dramatic increase $(I)$ in longitudinally oriented chains (I, arrows) 3 months after OBX. In $A-F$ frontal sections, dorsal is $u p$; in $H$ and $I$ sagittally oriented whole mounts, rostral is left and dorsal is $u p$. $L V$, Lateral ventricle. Scale bars: $A, D, H, I, 300 \mu \mathrm{m} ; B, C, E, F, 200 \mu \mathrm{m}$. 

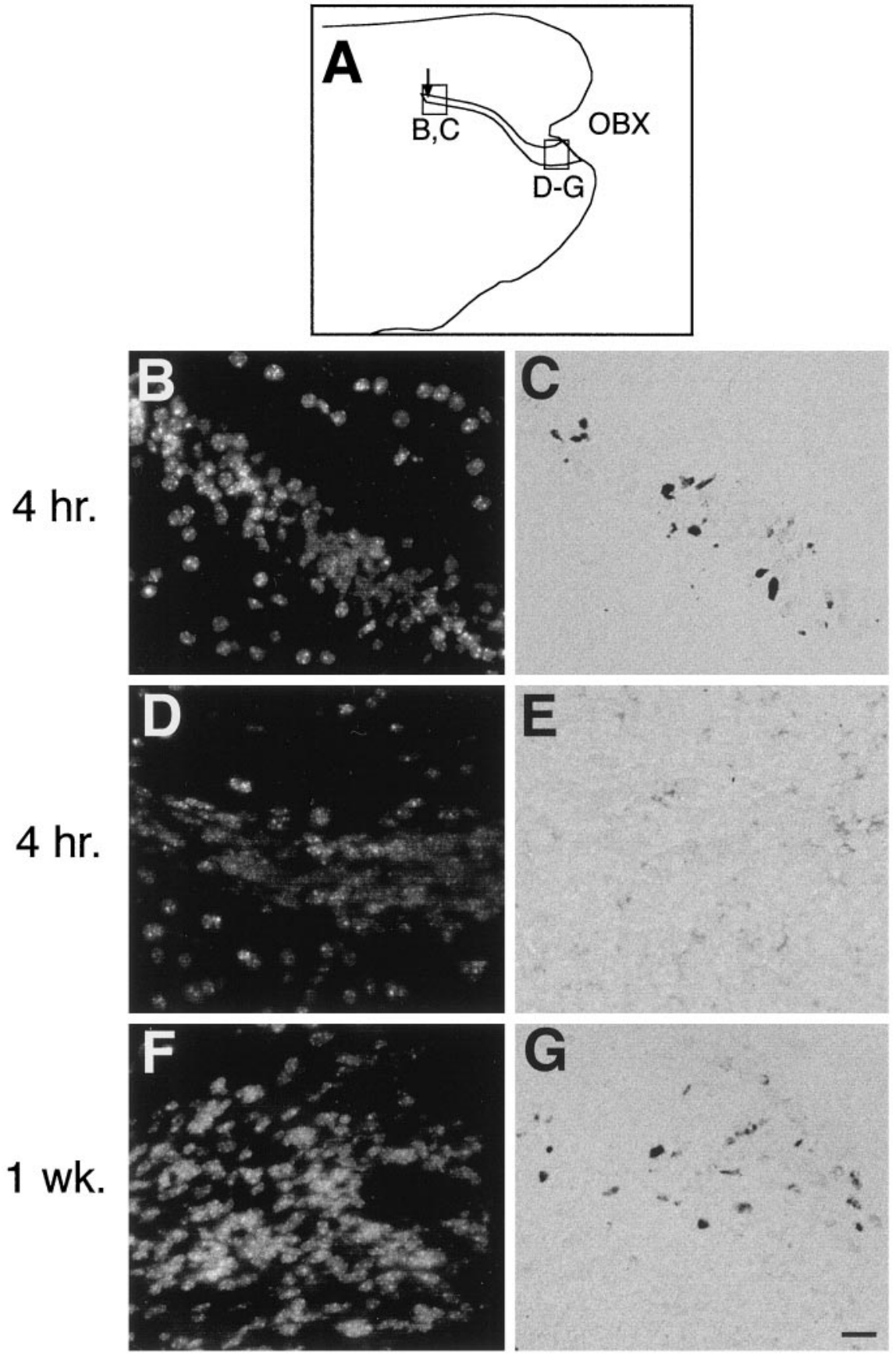

Figure 5. Rostral migration of SVZ cells labeled by microinjection of BrdU. $A$, The anterior SVZ was labeled by a local microinjection of $10 \mathrm{nl}$ of $\mathrm{BrdU}$ ( 10 $\mathrm{mg} / \mathrm{ml}$ ) (arrow) 2 weeks after OBX; the regions from which photomicrographs in $B-G$ were taken is indicated by the frames. $B, D, F$, Nuclear staining by Hoechst 33258. $C, E, G$, The same fields stained for BrdU. $B-E$, Four hours after microinjection, labeled cells were concentrated in the anterior SVZ and the caudal RMS $(B, C)$, but no labeled cells were found in the anterior RMS close to the site of $\mathrm{OB}$ excision $(D, E) . F, G$, One week after microinjection, BrdUlabeled cells were found all along the RMS, including the region next to the site of bulb excision. Scale bar, $20 \mu \mathrm{m}$.
The above results suggest that the increase in the size of the migratory pathways at the longer survival times extended caudally beyond the RMS into the SVZ. To visualize the network of chains in the SVZ after OBX, we dissected whole mounts (en face dissection) of the lateral wall of the lateral ventricle (Doetsch and Alvarez-Buylla, 1996) and immunostained them for PSA-NCAM. Three weeks and 3 months after OBX, an increase in the number and size of chains in the SVZ of the lateral wall of the lateral ventricle was observed. This increase was most noticeable 3 months after OBX (Fig. 4G,H) and was very dramatic in the longitudinally oriented chains in the dorsal part of this wall (Fig. $4 H$, arrows). PSA-NCAM-positive chains in this region amassed after OBX and became so dense that it was difficult to distinguish individual chains. These results indicate that the RMS and the SVZ network of migrating neuronal chains enlarge after OBX, suggesting that the number of young migrating neurons in these areas has increased.

\section{The rostral migration of SVZ cells persists after OBX}

To test whether SVZ precursor cells continue to migrate along the RMS when the bulb is removed, we labeled a restricted population of dividing cells in the SVZ of the lateral wall of the lateral ventricle with a microinjection of BrdU. In mice $(n=3)$ that had had their bulb removed for 2 weeks, $4 \mathrm{hr}$ after BrdU microinjection, labeled cells were restricted to the SVZ and caudal RMS near the site of injection (Fig. $5 B, C$ ). No labeled cells were observed in the intermediate or anterior RMS (Fig. $5 D, E)$. This indicates that BrdU did not diff use after microinjection and labeled cells only close to the injection site. One week after microinjection of BrdU in the SVZ of bulbectomized mice, 


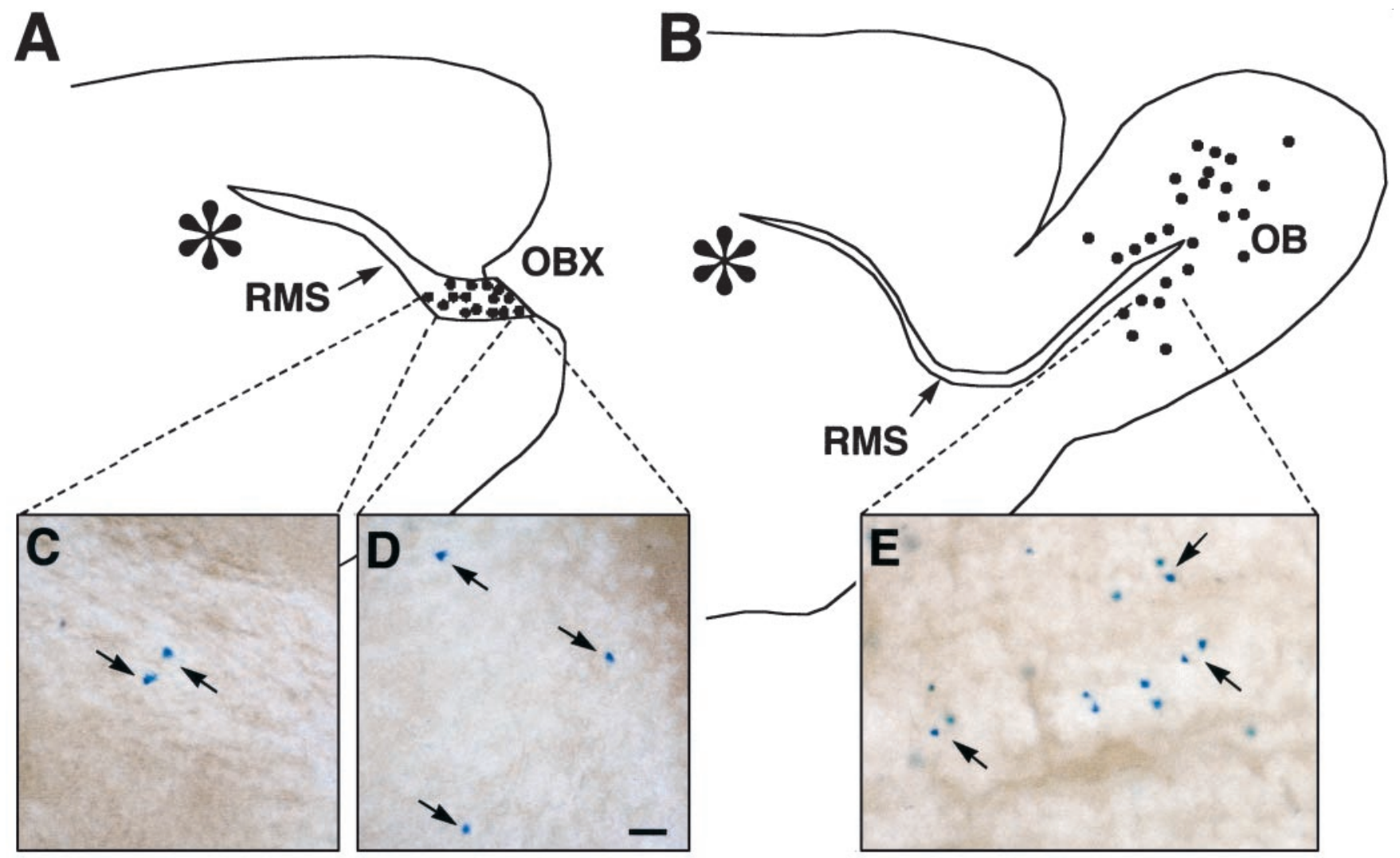

Figure 6. Grafted SVZ cells migrate rostrally after OBX. $A, B$, NSE::LacZ SVZ cells from P5 donor mice were grafted in the anterior SVZ (asterisks) of nontransgenic hosts in the OBX $(A)$ and in the contralateral control hemisphere $(B)$. This was done 2 and 8 weeks after OBX; figure shows results for the 8 week survival. Mice were killed 4 weeks after transplantation. $A, C, D$, On the bulbectomized side, cells migrated rostrally and could be detected along the RMS $(C)$ and close to the amputation site (filled circles). The small perinuclear $\beta$-galactosidase reaction product is typical of neurons in the NSE::LacZ transgenic mice $(C, D$, arrows). $B, E$, On the control side, SVZ precursors migrated rostrally into the OB $(E)$, where they were detected by the perinuclear reaction product in the granule layer $(B$, filled circles). No labeled cells were observed in the RMS of the control hemisphere. Scale bar, $10 \mu \mathrm{m}$.

labeled cells were found all along the RMS, including the most rostral region close to the site were the OB had been removed (Fig. $5 F, G)$.

This suggests that cells originating in the SVZ or caudal RMS migrated rostrally along the RMS $\sim 1.5 \mathrm{~mm}$ from the injection site. In the intact side, many labeled cells had reached the core of the $\mathrm{OB}$ as has been reported previously (Lois and Alvarez-Buylla, 1994). The rostral migration on the operated side was observed in mice that received the BrdU microinjection either $2(n=3)$ or 11 $(n=2)$ weeks after OBX. These results were replicated using $\left[{ }^{3} \mathrm{H}\right] \mathrm{T}$ microinjection $2(n=3)$ and $11(n=2)$ weeks after OBX (data not shown). As with BrdU, shortly after $\left[{ }^{3} \mathrm{H}\right] \mathrm{T}$ microinjection, labeled cells were found only close to the injection site, whereas at 1 week, labeled cells had migrated into the OB (Lois and Alvarez-Buylla, 1994) in the unoperated side. Likewise, in the bulbectomized hemisphere, 1 week after $\left[{ }^{3} \mathrm{H}\right] \mathrm{T}$ microinjection into the SVZ, labeled cells were observed in the rostral RMS close to the site of excision. This indicates that dividing cells originating in the SVZ continue to migrate anteriorly along the RMS, even when the OB had not been present for a few weeks.

\section{Grafted SVZ cells migrate rostrally and express NSE::LacZ}

To further confirm the rostral migration of SVZ cells in the absence of the OB, SVZ explants dissected from NSE::LacZ transgenic mice were grafted homotopically into the SVZ of nontransgenic CD-1 mice. The right $\mathrm{OB}$ had been removed in the host animals $2(n=3)$ or $8(n=3)$ weeks before transplantation. NSE-labeled cells have a small perinuclear deposit of $\beta$ galactosidase reaction (Lois and Alvarez-Buylla, 1994). Four weeks after transplantation, many $\beta$-galactosidase-positive cells were found in the $\mathrm{OB}$ on the unoperated side. No $\beta$-galactosidasepositive cells were present in the RMS of the control hemisphere (Fig. $6 B, D$ ). In contrast, many $\beta$-galactosidase-positive cells were present in the RMS of the bulbectomized hemisphere (Fig. 6A,C). These cells were in the rostral region of the RMS, proximal to the site of bulb excision. This experiment further confirms the rostral migration of SVZ cells in the absence of the OB and indicates that at least some of the cells that had migrated rostrally began expressing NSE.

\section{The proportion of proliferating RMS cells decreases after long-term removal of the $O B$}

Dividing cells are normally present in the RMS (Frazier-Cierpial and Brunjes, 1989; Corotto et al., 1994; Lois and Alvarez-Buylla, 1994; Menezes et al., 1995). We were interested in examining whether OBX might influence RMS proliferation. Three days, 3 weeks, or 3 months after unilateral OBX, BrdU was injected systemically to label dividing cells. Four hours after injection, BrdU-labeled cells made up over $8 \%$ of the total RMS cell population on the control side (Fig. 7). Three days after OBX, there was a small decrease in the percentage of proliferating cells that was not significant ( $p=0.15$; Mann-Whitney $U$ test) (Fig. 7). At three weeks after OBX, the percentage of proliferating cells 


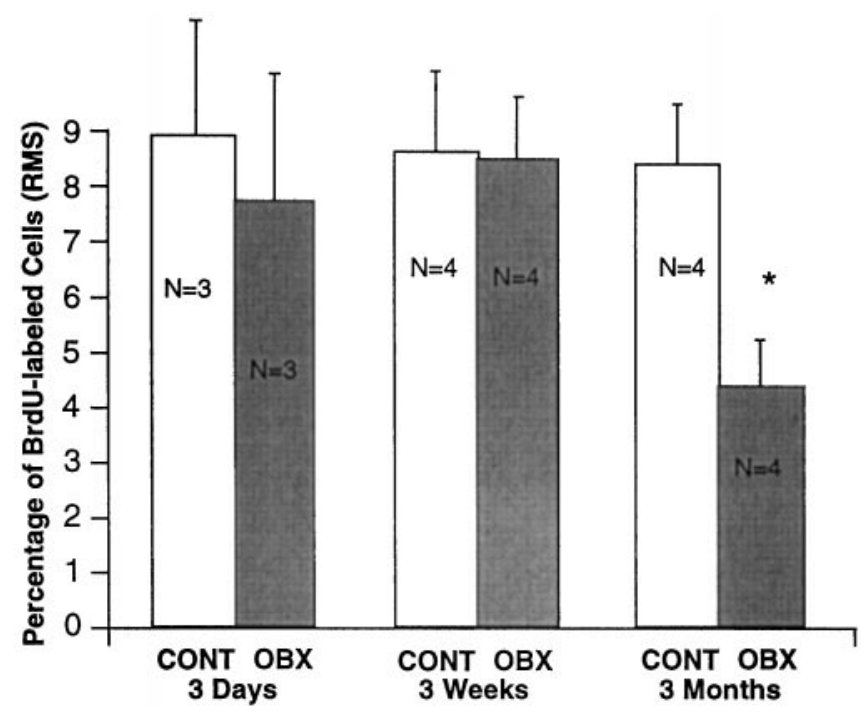

Figure 7. Percentage of BrdU-labeled cells in the RMS on the bulbectomized side $(O B X)$ and on the control side $(C O N T)$. No significant difference was observed at $3 \mathrm{~d}$ and 3 weeks, but by 3 months, a significant reduction in the percentage of BrdU-labeled cells occurs on the bulbectomized side. ${ }^{*} p=0.02$; Mann-Whitney $U$ test. Error bars indicate mean $\pm \mathrm{SD}$.

was similar in both the bulbectomized and control hemispheres (Fig. 7), indicating that the population of dividing cells had increased in the same proportion as the total number of RMS cells. The percentage of proliferating cells 3 months after OBX was significantly reduced to $<5 \%$ of the total RMS cells ( $p=$ 0.02; Mann-Whitney $U$ test) (Fig. 7).

\section{The proportion of dying RMS cells increases after OBX}

Dying cells in the RMS were detected by chromatin condensation (pyknosis) and by the TUNEL technique, which labels the nuclei of cells undergoing DNA fragmentation (Fig. 8). The TUNEL method detects DNA fragments before morphological changes are evident (Wood et al., 1993). We therefore used both techniques to detect dying cells in the RMS (Fig. $8 A, B$ ). Results with both techniques were similar. The percentage of dying cells in the RMS 3 weeks after OBX increased slightly, although not significantly (Fig. 8). By 3 months after OBX, the percentage of dying cells in the RMS increased significantly, with approximately twice as many pyknotic or TUNEL-labeled cells compared with control (Fig. 8). Dying cells at 3 weeks and 3 months after OBX were scattered all along the RMS in both control and bulbectomized hemispheres (Fig. 9). This indicates that the increase in cell death did not occur only close to the site of OBX but throughout the RMS.

\section{DISCUSSION}

Here, we show that cells in the RMS continue to proliferate and migrate after $\mathrm{OBX}$, indicating that the $\mathrm{OB}$ is not essential for these processes. Our results suggest that continual proliferation and migration in the absence of the $\mathrm{OB}$ result in the accumulation of precursors and a dramatic increase in the size of the RMS and SVZ. At 3 months after OBX, probably as a consequence of the increase in the number of cells in the RMS, the proportion of dividing RMS cells decreased by half and that of dying cells doubled.

\section{Proliferation}

The percentage of BrdU-labeled RMS cells 3 d and 3 weeks after OBX was similar to controls. Because RMS cell density was not affected by OBX, the number of dividing cells at 3 weeks increased proportionally to the increase in the size of the RMS $(\sim 30 \%)$. A change in the percentage of BrdU-labeled RMS cells was only observed at the longer survival (3 months), when it decreased by half. It is unlikely that the decrease in the labeling index observed at 3 months reflects the absence of bulb-secreted factors, although we cannot exclude this possibility. Instead, the increased number of cells that accumulate in the RMS and SVZ may over time downregulate cell production.

Because SVZ neuroblasts express PSA-NCAM (Rousselot et al., 1995; Doetsch et al., 1997) and the area of PSA-NCAM staining increased dramatically after OBX, the increased size of the RMS and SVZ is likely caused by the accumulation of neuroblasts. At the short survival, the increase in the size was only noticeable in the anterior RMS. This accumulation, however, extended throughout the SVZ network at the longer survival, supporting the notion that $\mathrm{OB}$ neurons originate not only in the anterior but also in the caudal SVZ (Doetsch and Alvarez-Buylla, 1996). Neuroblasts in the SVZ and RMS continue to divide (Lois and Alvarez-Buylla, 1994; Menezes et al., 1995). The decrease in the percentage of BrdU-labeled cells at 3 months suggests that migrating neuroblasts downregulate their proliferation or die before they undergo BrdU incorporation. Alternatively, this decrease could be caused by the accumulation of nonmitotic cells in the RMS, diluting the population of dividing cells. In either case, our results suggest that the $\mathrm{OB}$ is not essential for continual production of neuroblasts in the SVZ and their proliferation in the RMS.

Two previous studies have found that olfactory deprivation has no effect on the proliferation of most cells en route to the bulb (Frazier-Cierpial and Brunjes, 1989; Corotto et al., 1994), although under these conditions the RMS does not increase in size. Naris closure results in a decrease in BrdU-labeled cells within the OB and in the RMS close to it (Corotto et al., 1994). In our study, the anterior part of the RMS was removed, and we cannot conclude that the OB exerts no control on the proliferation of RMS cells once these cells are inside or close to the bulb.

\section{Migration}

Two independent experiments indicate that SVZ precursors continued to migrate rostrally in the absence of the OB: (1) SVZ cells labeled locally within the SVZ migrated anteriorly through the RMS, and 1 week later could be found close to the site of OB excision; and (2) transplants of SVZ cells from an NSE::lacZ mouse into CD-1 mice indicate that SVZ precursor cells migrated rostrally in the absence of the $\mathrm{OB}$. The rostral migration occurred in animals 3 months after OBX, suggesting that bulb-derived factors were not required for the maintenance of the pathway or the rostral movement of cells along this route. However, we do not know whether the rate of migration was affected after OBX. We found no evidence of precursors straying away from this pathway, despite a doubling in the size of the RMS.

RMS precursors are primarily oriented in the direction of the OB (Kishi, 1987; Luskin, 1993), suggesting that directional cues guide these cells rostrally. The mechanism for this directional guidance remains unknown. When SVZ precursors are explanted in vitro, these cells assemble as chains, but migration within these chains is not directional, suggesting that guidance cues are lost after explantation (Wichterle et al., 1997). Placement of a small 

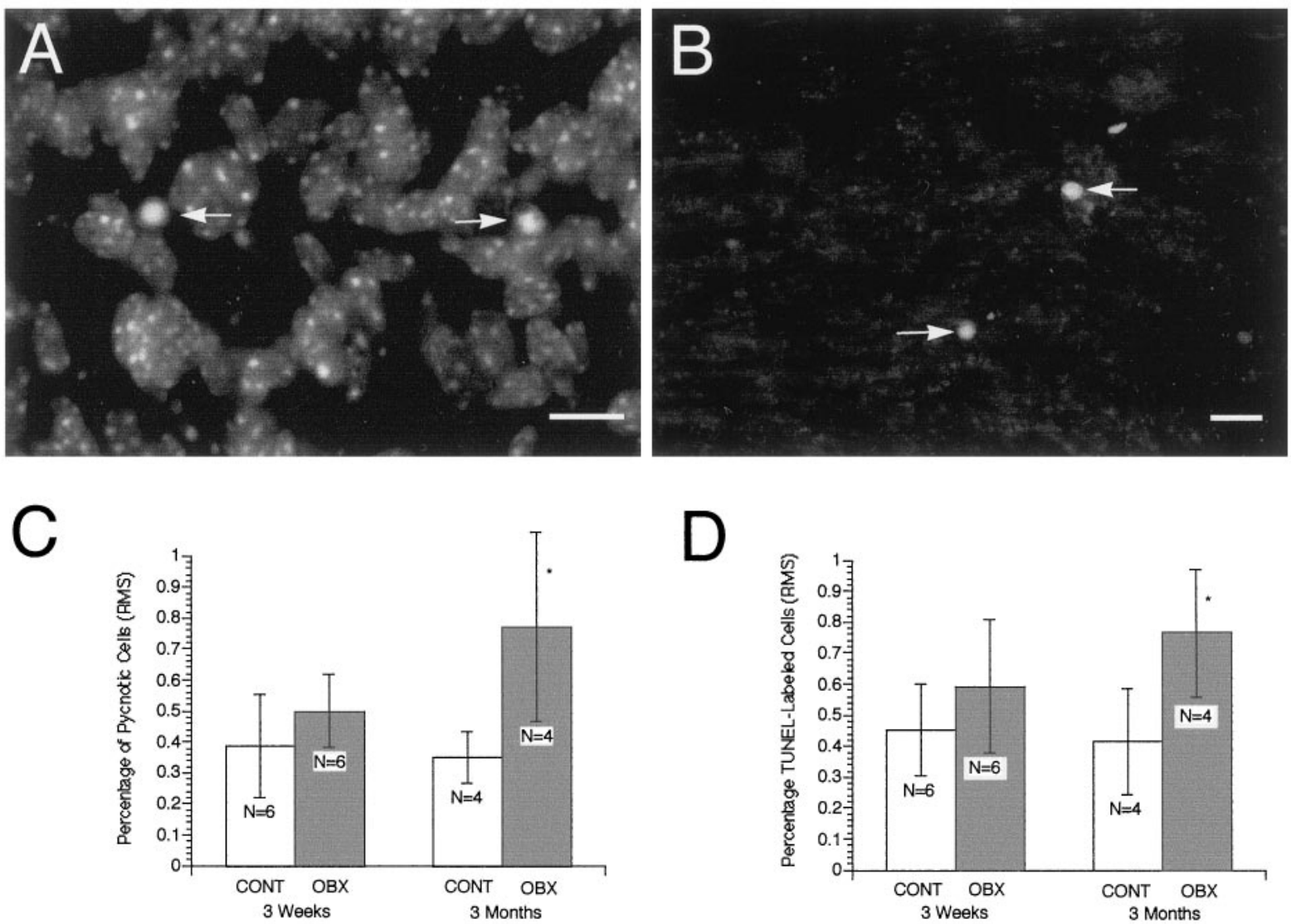

Figure 8. Effect of OBX on the percentage of dying cells in the RMS. A, Pyknotic cells were counted in Hoechst 33258-stained sections and identified by their bright condensed chromatin in single or multiple clumps (arrows). B, Quantification of dying cells was also done using TUNEL. TUNEL-labeled cells were identified by their bright fluorescent nuclei (arrows). $C$, Percentage of pyknotic cells in the RMS in control (CONT) and bulbectomized (OBX) hemispheres 3 weeks and 3 months after OBX. A significant increase in the proportion of pyknotic cells in the bulbectomized hemisphere compared with the control hemisphere was observed at 3 months; ${ }^{*} p=0.02$; Mann-Whitney $U$ test. $D$, Percentage of TUNEL-labeled cells in the RMS 3 weeks and 3 months after OBX. A significant increase in the percentage of TUNEL-labeled cells in the RMS was observed on the bulbectomized hemisphere at 3 months. Error bars indicate mean \pm SD. Scale bars, $20 \mu \mathrm{m}$.

Figure 9. Distribution of pyknotic cells (open circles) and TUNEL-labeled cells (filled circles) in the RMS 3 weeks and 3 months after OBX. Pyknotic and TUNEL-labeled cells are scattered throughout the RMS in the bulbectomized $(A)$ and control $(B)$ hemispheres. Each diagram is the superimposed composite of four sections, one section per mouse $(n=4)$ through the middle of the RMS.
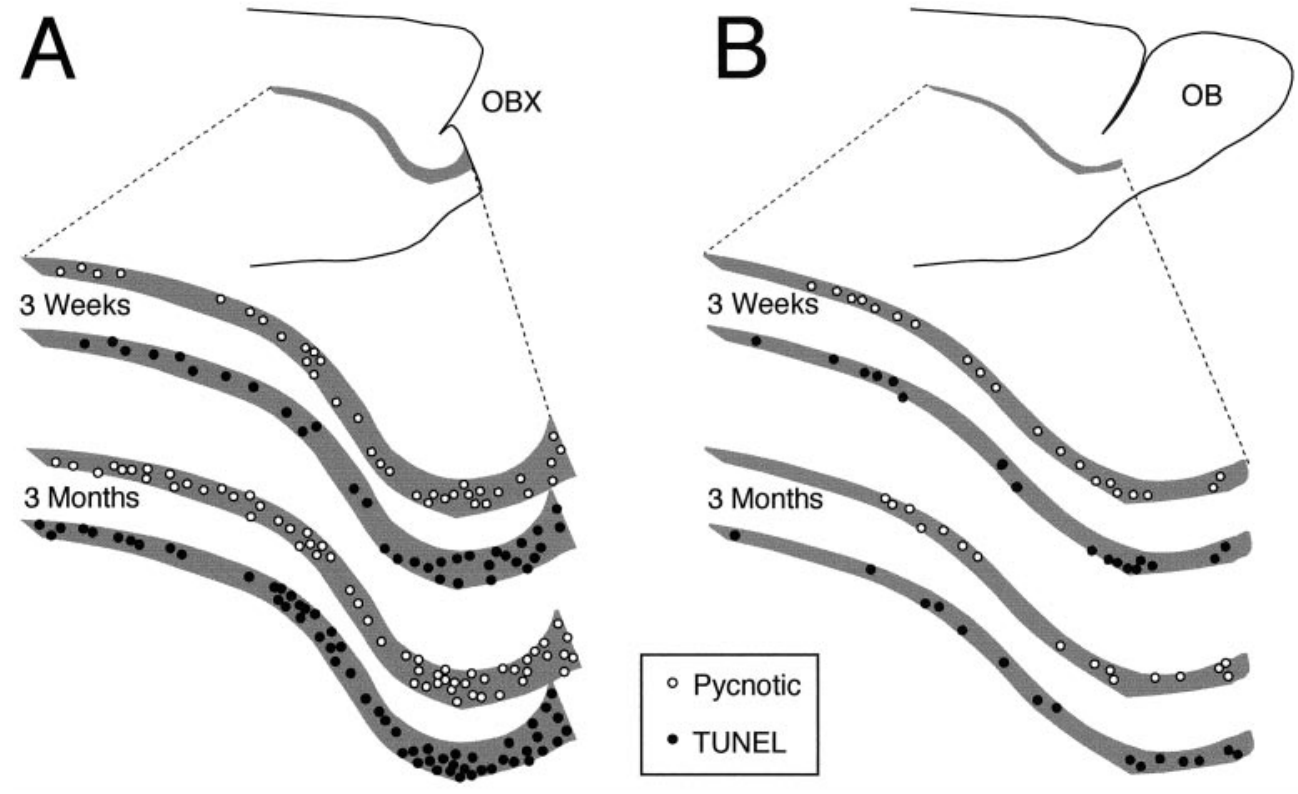
fragment of the OB close to an SVZ explant does not influence the direction of migration of cells in vitro (Hu and Rutishauser, 1996; H. Wichterle and A. Alvarez-Buylla, unpublished observations). The present in vivo results further support the notion that directional migration does not depend on the OB but that guidance factors are probably extrinsic to this structure.

In vitro results suggested that a chemorepulsive factor secreted by the septum may guide SVZ cell migration rostrally ( $\mathrm{Hu}$ and Rutishauser, 1996). However, no evidence exists for a chemorepulsive activity in the lateral wall of the lateral ventricle, where most SVZ migration occurs in adult mice. A chemorepulsive factor secreted in the caudal telencephalon could explain why cells continue to move forward in the absence of the OB. Directional information may also be inherent to the migrating cells and their pathway. Specialized astrocytes are present along the migratory path in the RMS (Lois et al., 1996) and in the OB (Bailey and Shipley, 1993; Chiu and Greer, 1996). These astrocytes and the extracellular matrix associated to them (Jankovski and Sotelo, 1996; Thomas et al., 1996) may help restrict and guide the rostral migration of SVZ precursors.

NSE::LacZ SVZ cells grafted into the SVZ of a bulbectomized hemisphere migrate rostrally and differentiate into cells that express NSE within the RMS. The expression of NSE suggests that these cells have differentiated into neurons (Schmechel and Marangos, 1983). In the control hemisphere, cells are NSEpositive only when they reach the OB. Two other observations are consistent with a self-autonomous capacity of SVZ precursors to differentiate into neurons: (1) SVZ cells explanted in vitro give rise to neurons spontaneously in culture (Lois and AlvarezBuylla, 1993; Kirschenbaum and Goldman, 1995); and (2) migrating precursors throughout the SVZ and RMS already express some neuron-specific markers (Menezes and Luskin, 1994; Doetsch and Alvarez-Buylla, 1996). However, recent evidence indicates that some astrocytes also express NSE (Lin and Matesic, 1994; D. Herrera, J. M. Garcia-Verdugo, and A. Alvarez-Buylla, unpublished results). Further work will be required to determine the phenotype of cells that express NSE in the RMS after OBX.

\section{Cell death}

Our results using TUNEL and pyknotic cell counts confirm previous studies showing that cell death occurs normally in the RMS (Brunjes and Armstrong, 1996; Jankovski and Sotelo, 1996; Lois et al., 1996). Three weeks after OBX, the percent of dying cells in the RMS was similar to controls, but by 3 months, the percent of RMS dying cells doubled. This suggests that cell death in the RMS is not directly controlled by the OB. However, we cannot discard the possibility that RMS cell death within the bulb or close to the OB may be regulated by factors that the bulb secretes. In neonate rats, olfactory deprivation increases the number of dying cells in the RMS within the OB (Najbauer and Leon, 1995). The increased numbers of dying cells that we observed at the longer survivals may have resulted from overcrowding in the SVZ and RMS or by the demise of cells differentiating without an appropriate target.

\section{Conclusion}

The number of cells in the RMS is increased by cell immigration and division; it is decreased by cell emigration and death. Within the first weeks after OBX, the proportion of dividing and dying cells in the RMS was not significantly affected, indicating that the number of dividing and dying cells increased proportionally to the size of the RMS. However, migration of cells into the RMS continues, but presumably emigration stops by eliminating the OB. The increase in the size of the RMS most likely results from an imbalance in RMS cell immigration and emigration. This assumes that BrdU-labeling, pyknotic, and TUNEL indexes are an accurate representation of rates of cell division and death within the RMS. Increases in the size of the SVZ have also been observed after large lesions of the frontal and parietal cortex (Szele and Chesselet, 1996) or after a lesion of the fimbria fornix (Weinstein et al., 1996). Our results suggest that large changes in the size of migration routes, including the SVZ, may occur as a consequence of interfering with or preventing SVZ neuronal precursors from reaching the OB.

The present results demonstrate that the $\mathrm{OB}$ is not required for the continual production and migration of SVZ precursors, which otherwise seem to be specifically targeted to this brain structure. Neurogenesis in the SVZ and RMS appear to be constitutive, and these cells use migratory cues independent of the OB. Local signals within the SVZ and RMS may ensure a constant supply of adult-formed young neurons and prevent the uncontrolled growth of this germinal layer.

\section{REFERENCES}

Ahmed S, Reynolds BA, Weiss S (1995) BDNF enhances the differentiation but not the survival of CNS stem cell-derived neuronal precursors. J Neurosci 15:5765-5778.

Altman J (1969) Autoradiographic and histological studies of postnatal neurogenesis. IV. Cell proliferation and migration in the anterior forebrain, with special reference to persisting neurogenesis in the olfactory bulb. J Comp Neurol 137:433-458.

Alvarez-Buylla A (1997) Mechanism of migration of olfactory bulb interneurons. Semin Cell Dev Biol 8:207-213.

Alvarez-Buylla A, Vicario DS (1988) Simple microcomputer system for mapping tissue sections with the light microscope. J Neurosci Methods 25:165-173

Alvarez-Buylla A, Buskirk DR, Nottebohm F (1987) Monoclonal antibody reveals radial glia in adult avian brain. J Comp Neurol 264:159-170.

Alvarez-Buylla A, Theelen M, Nottebohm F (1988) Birth of projection neurons in the higher vocal center of the canary forebrain before, during, and after song learning. Proc Natl Acad Sci USA 85:8722-8726.

Bailey MS, Shipley MT (1993) Astrocyte subtypes in the rat olfactory bulb: morphological heterogeneity and differential laminar distribution. J Comp Neurol 328:501-526.

Bayer SA (1983) ${ }^{3} \mathrm{H}$-Thymidine-radiographic studies of neurogenesis in the rat olfactory bulb. Exp Brain Res 50:329-340.

Bonfanti L, Theodosis DT (1994) Expression of polysialylated neural cell adhesion molecule by proliferating cells in the subependymal layer of the adult rat, in its rostral extension and in the olfactory bulb. Neuroscience 62:291-305.

Brunjes PC, Armstrong AM (1996) Apoptosis in the rostral migratory stream of the developing rat. Dev Brain Res 92:219-222.

Chao MV (1992) Neurotrophin receptors: a window into neuronal differentiation. Neuron 9:583-593.

Chiu K, Greer CA (1996) Immunocytochemical analyses of astrocyte development in the olfactory bulb. Dev Brain Res 95:28-37.

Corotto FS, Henegar JA, Maruniak JA (1993) Neurogenesis persists in the subependymal layer of the adult mouse brain. Neurosci Lett 149:111-114.

Corotto FS, Henegar JR, Maruniak JA (1994) Odor deprivation leads to reduced neurogenesis and reduced neuronal survival in the olfactory bulb of the adult mouse. Neuroscience 61:739-744.

Craig CG, Tropepe V, Morshead CM, Reynolds BA, Weiss S, Van der Kooy D (1996) In vivo growth factor expansion of endogenous subependymal neural precursor cell populations in the adult mouse brain. J Neurosci 16:2649-2658.

Cremer H, Lange R, Christoph A, Plomann M, Vopper G, Roes J, Brown R, Baldwin S, Kraemer P, Scheff S, Barthels D, Rajewsky K, Wille W (1994) Inactivation of the N-CAM gene in mice results in size reduction of the olfactory bulb and deficits in spatial learning. Nature 367:455-459.

Doetsch F, Alvarez-Buylla A (1996) Network of tangential pathways for 
neuronal migration in adult mammalian brain. Proc Natl Acad Sci USA 93:14895-14900.

Doetsch F, Garcia-Verdugo JM, Alvarez-Buylla A (1997) Cellular composition and three-dimensional organization of the subventricular germinal zone in the adult mammalian brain. J Neurosci 17:5046-5061.

Farbman AI (1990) Olfactory neurogenesis: genetic or environmental controls. Trends Neurosci 13:362-365.

Forss-Petter S, Danielson PE, Catsicas S, Battenberg E, Price J, Nerenberg M, Sutcliffe JG (1990) Transgenic mice expressing $\beta$-galactosidase in mature neurons under neuron-specific enolase promoter control. Neuron 5:187-197.

Frazier-Cierpial L, Brunjes PC (1989) Early postnatal cellular proliferation and survival in the olfactory bulb and rostral migratory stream of normal and unilaterally odor-deprived rats. J Comp Neurol 289:481-492.

Gavrieli Y, Sherman Y, Ben-Sasson SA (1992) Identification of programmed cell death in situ via specific labelling of nuclear DNA fragmentation. J Cell Biol 119:493-501.

Gritti A, Cova L, Parati EA, Galli R, Vescovi AL (1995) Basic fibroblast growth factor supports the proliferation of epidermal growth factorgenerated neuronal precursor cells of the adult mouse CNS. Neurosci Lett 185:151-154.

Gritti A, Parati EA, Cova L, Frolichsthal P, Galli R, Wanke E, Faravelli L, Morassutti DJ, Roisen F, Nickel DD, Vescovi AL (1996) Multipotential stem cells from the adult mouse brain proliferate and self-renew in response to basic fibroblast growth factor. J Neurosci 16:1091-1100.

Hinds JW (1968) Autoradiographic study of histogenesis in the mouse olfactory bulb. I. Time of origin of neurons and neuroglia. J Comp Neurol 134:287-304.

Holcomb JD, Mumm JS, Calof AL (1995) Apoptosis in the neuronal lineage of the mouse olfactory epithelium: regulation in vivo and in vitro. Dev Biol 172:307-323.

Hu HY, Rutishauser U (1996) A septum-derived chemorepulsive factor for migrating olfactory interneuron precursors. Neuron 16:933-940.

Jankovski A, Sotelo C (1996) Subventricular zone-olfactory bulb migratory pathway in the adult mouse: cellular composition and specificity as determined by heterochronic and heterotopic transplantation. J Comp Neurol 371:376-396.

Kirschenbaum B, Goldman SA (1995) Brain-derived neurotrophic factor promotes the survival of neurons arising from the adult rat forebrain subependymal zone. Proc Natl Acad Sci USA 92:210-214.

Kishi K (1987) Golgi studies on the development of granule cells of the rat olfactory bulb with reference to migration in the subependymal layer. J Comp Neurol 258:112-124.

Kuhn HG, Winkler J, Kempermann G, Thal LJ, Gage FH (1997) Epidermal growth factor and fibroblast growth factor-2 have different effects on neural progenitors in the adult rat brain. J Neurosci 17:5820-5829.

Lin RCS, Matesic DF (1994) Immunohistochemical demonstration of neuron-specific enolase and microtubule-associated protein 2 in reactive astrocytes after injury in the adult forebrain. Neuroscience 60:11-16.

Linden R (1994) The survival of developing neurons: a review of afferent control. Neuroscience 4:671-682.

Lois C, Alvarez-Buylla A (1993) Proliferating subventricular zone cells in the adult mammalian forebrain can differentiate into neurons and glia. Proc Natl Acad Sci USA 90:2074-2077.

Lois C, Alvarez-Buylla A (1994) Long-distance neuronal migration in the adult mammalian brain. Science 264:1145-1148.

Lois C, Garcia-Verdugo JM, Alvarez-Buylla A (1996) Chain migration of neuronal precursors. Science 271:978-981.

Luskin MB (1993) Restricted proliferation and migration of postnatally generated neurons derived from the forebrain subventricular zone. Neuron 11:173-189.

Menezes JRL, Luskin MB (1994) Expression of neuron-specific tubulin defines a novel population in the proliferative layers of the developing telencephalon. J Neurosci 14:5399-5416.

Menezes JRL, Smith CM, Nelson KC, Luskin MB (1995) The division of neuronal progenitor cells during migration in the neonatal mammalian forebrain. Mol Cell Neurosci 6:496-508.

Monti-Graziadei AG, Graziadei PPC (1992) Sensory reinnervation after partial removal of the olfactory bulb. J Comp Neurol 316:32-44.

Najbauer J, Leon M (1995) Olfactory experience modulates apoptosis in the developing olfactory bulb. Brain Res 674:245-251.

Ono K, Tomasiewicz H, Magnuson T, Rutishauser U (1994) N-CAM mutation inhibits tangential neuronal migration and is phenocopied by enzymatic removal of polysialic acid. Neuron 13:595-609.

Reynolds B, Weiss S (1992) Generation of neurons and astrocytes from isolated cells of the adult mammalian central nervous system. Science 255:1707-1710.

Richards LJ, Kilpatrick TJ, Bartlett PF (1992) De novo generation of neuronal cells from the adult mouse brain. Proc Natl Acad Sci USA 89:8591-8595.

Rougon G, Dubois C, Buckley N, Magnani JL, Zollinger W (1986) A monoclonal antibody against meningococcus group $\mathrm{B}$ polysaccharides distinguishes embryonic from adult N-CAM. J Cell Biol 103:2429-2437.

Rousselot P, Lois C, Alvarez-Buylla A (1995) Embryonic (PSA) N-CAM reveals chains of migrating neuroblasts between the lateral ventricle and the olfactory bulb of adult mice. J Comp Neurol 351:51-61.

Schmechel DE, Marangos PJ (1983) Neuron-specific enolase (NSE): specific cellular and functional marker for neurons and neuroendocrine cells. In: Current methods in cellular neurobiology (Barker J, McKelvey J, eds), pp 1-62. New York: Wiley.

Schwob JE, Szumowski KE, Stasky AA (1992) Olfactory sensory neurons are trophically dependent on the olfactory bulb for their prolonged survival. J Neurosci 12:3896-3919.

Slotnick BM, Leonard CM (1975) A stereotaxic atlas of the albino mouse forebrain. Rockville, MD: Dhew.

Szele FG, Chesselet MF (1996) Cortical lesions induce an increase in cell number and PSA-NCAM expression in the subventricular zone of adult rats. J Comp Neurol 368:439-454.

Tessier-Lavigne M, Placzek M, Lumsden AGS, Dodd J, Jessell TM (1988) Chemotropic guidance of developing axons in the mammalian central nervous system. Nature 336:775-778.

Thomas LB, Gates MA, Steindler DA (1996) Young neurons from the adult subependymal zone proliferate and migrate along an astrocyte, extracellular matrix-rich pathway. Glia 17:1-14.

Tomasiewicz H, Ono K, Yee D, Thompson C, Goridis C, Rutishauser U, Magnuson T (1993) Genetic deletion of a neural cell adhesion molecule variant (N-CAM 180) produces distinct defects in the central nervous system. Neuron 11:1163-1174.

Weinstein DE, Burrola P, Kilpatrick TJ (1996) Increased proliferation of precursor cells in the adult rat brain after targeted lesioning. Brain Res 743:11-16.

Wichterle H, Garcia-Verdugo JM, Alvarez-Buylla A (1997) Direct evidence for homotypic, glia-independent neuronal migration. Neuron 18:779-791.

Wood KA, Dipasquale B, Youle RJ (1993) In situ labeling of granule cells for apoptosis-associated DNA fragmentation reveals different mechanisms of cell loss in developing cerebellum. Neuron 11:621-632.

Yaginuma H, Shiga T, Oppenheim RW (1994) Early developmental patterns and mechanisms of axonal guidance of spinal interneurons in the chick embryo spinal cord. Prog Neurobiol 44:249-278. 